\title{
A nurse-led intervention reduced risk factors, anxiety, and depression in patients waiting for CABG
}

McHugh F, Lindsay GM, Hanlon P, et al. Nurse led shared care for patients on the waiting list for coronary artery bypass surgery: a randomised controlled trial. Heart 2001 Sep;86:317-23.

\section{QUESTION: Does nurse-led, shared care for patients on a waiting list for coronary artery bypass grafting (CABG) reduce coronary artery disease (CAD) risk factors, anxiety, and depression?}

\section{Design}

Randomised (unclear allocation concealment*), unblinded,* controlled trial with follow up at $\{1$ week before scheduled surgery\}†.

Source of funding: National Health Service Management Executive.

For correspondence: Dr G M Lindsay, University of Glasgow, Glasgow, Scotland, UK. GLIZ@clinmed.gla.ac.uk.

\section{Setting}

Glasgow Royal Infirmary University NHS Trust, Glasgow, Scotland, UK.

\section{Patients}

121 patients who were on an elective $\mathrm{CABG}$ waiting list. $81 \%$ (mean age $62 \mathrm{y}, 76 \%$ men) were included in the analysis.
Nurse-led care v usual care for patients waiting for coronary artery bypass grafting

\begin{tabular}{lllll}
$\begin{array}{l}\text { Outcomes at } 1 \text { week } \\
\text { before surgery }\end{array}$ & Intervention & $\begin{array}{l}\text { Usual } \\
\text { care }\end{array}$ & RRR (95\% CI) & NNT (Cl) \\
Currently smoking & $2 \%$ & $18 \%$ & $89 \%(36$ to 98$)$ & $7(4$ to 20$)$ \\
\hline Systolic BP $\geqslant 140 \mathrm{~mm} \mathrm{Hg}$ & $27 \%$ & $56 \%$ & $52 \%(20$ to 72$)$ & $4(3$ to 11$)$ \\
\hline Diastolic BP $\geqslant 90 \mathrm{~mm} \mathrm{Hg}$ & $2 \%$ & $38 \%$ & $95 \%(71$ to 99$)$ & $3(2$ to 5$)$ \\
\hline
\end{tabular}

$\ddagger \mathrm{BP}=$ blood pressure. Other abbreviations defined in glossary; RRR, NNT, and $\mathrm{Cl}$ calculated from data in article.

\section{COMMENTARY}

The treatment effects found in the study by McHugh et al are impressive, however, the study has a major limitation. Observers of the key outcome measures were aware of study-group assignments and apparently were actively involved in the intervention. It is troubling that the study groups did not differ much for serum cholesterol concentration: the most objective outcome measure. This finding introduces the possibility of bias in the other assessments. Some of the patients in the active group might have distorted their reports to please the therapists. A similar observation was reported in the Multiple Risk Factor Intervention Trial (MRFIT), ${ }^{1}$ in which self reported smoking cessation by some men in the intervention group was not confirmed by objective measurement with serum thiocyanate. Interestingly, the self reported smoking cessation rates of men in the MRFIT usual-care group were reliable. One possible explanation is that some of the men in the intervention group misrepresented their smoking status to please the therapists or to avoid more intensive intervention.

Bias can be introduced into studies in many ways. It can be conscious or unconscious and is almost always unintentional. To be convincing, the study by McHugh et al requires assessment of outcomes by using objective indices of smoking and automated measurement of blood pressure, which are free of observer bias.

The results of this study suggest that a nurse liaison risk factor intervention for high risk patients may have major benefits. Future trials that pay careful attention to minimising bias in study measurements are needed to confirm these impressive findings.

$$
\begin{array}{r}
\text { Richard Grimm III, MD, MPH, PhD } \\
\text { University of Minnesota } \\
\text { Minneapolis, Minnesota, USA }
\end{array}
$$

1 Multiple Risk Factor Intervention Trial Research Group. Multiple Risk Factor Intervention Trial. Risk factor changes and mortality results. JAMA 1982;248:1465-77.

\section{Intervention}

62 patients were allocated to nurse-led care. A specialist cardiac liaison nurse assessed the patients' needs to determine the content of monthly education sessions, which were alternatively led by the liaison nurse in the patients' homes and by the general practice team nurse in the practice clinic. Interventions addressing behavioural risk factors were based on the patient's readiness to change. The liaison nurse provided tailored information about the surgery, hospital stay, and recuperation. The liaison nurse was available by telephone during regular working hours; calls to an answering machine were returned within 1 working day. 59 patients were allocated to usual care.

\section{Main outcome measures}

Smoking, body mass index (BMI), blood pressure, plasma cholesterol concentrations, physical activity, general health status (36-item Short Form Health Survey [SF-36]), and anxiety and depression (Hospital Anxiety and Depression Scale).

\section{Main results}

The intervention and usual care groups had similar mean waiting times for CABG (8.5 $v 8.3 \mathrm{mo})$. At follow up, fewer patients in the intervention group than in the usual care group were smoking, had systolic blood pressure $\geqslant 140 \mathrm{~mm} \mathrm{Hg}$, or had diastolic blood pressure $\geqslant 90 \mathrm{~mm} \mathrm{Hg}$ (table). Total cholesterol concentration was unchanged in the control group (5.6 mmol/l), but dropped from 5.8 to $5.1 \mathrm{mmol} / \mathrm{l}$ in the intervention group: a significant difference between the groups $(\mathrm{p}=0.003)$. BMI decreased by $1.0 \mathrm{~kg} / \mathrm{m}^{2}$ in the intervention group and increased in the control group ( $p<0.001$ for the difference between groups). Mean time spent exercising increased in the intervention group by $33 \%$ ( $75 \mathrm{~min} / \mathrm{wk}$ ) but decreased in the usual care group by $16 \%(31 \mathrm{~min} / \mathrm{wk})(\mathrm{p}<0.01)$. The intervention group had improved mean scores on all dimensions of the SF-36, whereas the usual care group had decreased scores on all dimensions ( $p$ values for mean change in scores ranged from 0.0 to 0.005 ). Nurse-led care was associated with decreased anxiety and depression scores ( $\mathrm{p}<0.01$ for both).

\section{Conclusion}

For patients waiting for coronary artery bypass grafting, a nurse-led, shared-care intervention reduced coronary artery disease risk factors, anxiety, and depression.

*See glossary.

$\dagger$ Information provided by author. 